\title{
THE IMPACT OF A GENERAL PRACTICE STAFFED CASUALTY SERVICE ON OVERALL PRIMARY MEDICAL SERVICES
}

\author{
Patrick Bolton and Michael Mira \\ Department of General Practice \\ University of Sydney
}

\section{Michael Jones}

Jones and Just Data Analysts

The Balmain Hospital General Practice Casualty (GPC) is a GP-staffed casualty-style service that meets the needs of the local community when local general practitioner services are not available. This article describes the effects of the GPC on the volume of services provided by nearby general practices.

The GPC seeks to provide primary medical care to patients. In Australia, primary medical care conditions have been accepted to be those that 'could be competently managed by a general practitioner in a well equipped surgery'. ${ }^{1}$

The GPC model has similarities with minor injury units, 2,3 and services provided by GPs to patients in emergency departments. ${ }^{4-7}$ Patients of the GPC are more satisfied than similar patients seen in emergency departments, and have similar health outcomes. ${ }^{8}$

The GPC was established in September 1993 and replaced a small emergency department. At the time of this rolechange, the emergency department was treating an average of 50 patients per day, of whom eight arrived by ambulance and eight were admitted. On this basis, it is estimated that the emergency department saw approximately 40 primary care patients per day. Immediately after the role change, the GPC saw 33 patients per day. By 2000, this had risen to 45 patients per day. At this time an average of 2.5 patients were either admitted to Balmain Hospital or transferred to another hospital for admission each day. Assuming that patients requiring admission are not suitable for primary care, in 2000 the GPC treated approximately 40 primary care patients per day.

From a policy perspective, one concern about such new services is that they may increase expenditure by addressing previously unmet need. ${ }^{10}$ It is possible to examine this hypothesis for the GPC using data collected by the Health Insurance Commission (HIC).

\section{TABLE 1}

THE LOCALITIES USED FOR THIS ANALYSIS

\begin{tabular}{|lll|}
\hline Localities & $\begin{array}{l}\text { Approximate } \\
\text { Area } \mathbf{( k m}^{2} \text { ) }\end{array}$ & $\begin{array}{l}\text { Population } \\
\text { (1991 census) }\end{array}$ \\
\hline $\begin{array}{l}\text { GPC catchment area } \\
\text { Eastern part of Central }\end{array}$ & 12 & 58,147 \\
$\begin{array}{l}\text { Sydney Health Area } \\
\text { Western part of Central } \\
\text { Sydney Health Area }\end{array}$ & 60 & 113,148 \\
\hline
\end{tabular}

The HIC administers Medicare, the universal system of health insurance that is available to everyone normally resident in Australia except for foreign diplomats and their dependents. ${ }^{10,11}$ A scheduled fee is paid by Medicare for the majority of services provided by general practitioners. ${ }^{10,11}$ Services that are not eligible for Medicare include those provided to eligible veterans and their dependants, services provided under certain types of insurance including motor vehicle and workers compensation insurance, and services not necessarily for patient care, such as medical examinations for employment purposes. ${ }^{10,11}$ These exclusions affect only a small proportion of general practitioner consultations and are likely to have remained proportionate to services billed under Medicare in recent decades. For this reason data about services provided under Medicare have been used as the basis for reviewing time series data about services provided by general practitioners by the Australian Institute of Health and Welfare and the General Practice Branch of the Commonwealth Department of Health and Family Services. ${ }^{10,11}$ The same approach will be used here.

\section{METHOD}

Three geographical areas within the Central Sydney Area Health Service were defined using postcodes. Details of these are provided in Table 1. Aggregate data were provided by the HIC about the number of GP consultations provided in each of these localities for each quarter commencing with September 1984 until September 1996.

Demographic data about the proportion of males and females in each five-year age group in each of the three localities were provided by the Australian Bureau of Statistics (ABS) from the 1986 and 1991 national censuses. These data were used to linearly interpolate and extrapolate quarterly demographic data for the period for which HIC data had been obtained. Population changes between censuses were small and so linear projections are thought to be appropriate.

The results of the third national survey of morbidity in general practice in Australia (AMTS) were reviewed to determine the pattern of use of GP services by different age and sex groups. ${ }^{12}$ The AMTS is a national survey of the services provided by a representative stratified random sample of 495 Australian GPs. This suggested that the proportion of services required by different demographic segments of the population falls in to five distinct groups. These are:

- children less than 15 years of age;

- adult males;

- adult females;

- males older than 65 years;

- females older than 65 years. 
Accordingly, the demographic data was aggregated into these five categories.

The generalised estimating equation (GEE) model was used to analyse the longitudinal GP consultation data available to gain some insight into the impact of the opening of the GPC on consultations in the three localities taking into account the changing age and sex distributions of the population. The model regressed the number of encounters on indicator variables for localities, the GPC being open or not, age and gender, with the latter two independent variables representing proportions by age and sex category. In addition the model included interactions between location and GPC status. The interaction term was of primary interest in the analysis since it compares locations in terms of change after the introduction of the GPC and therefore controls for changes in contemporary but extraneous factors. The statistical model was parameterised such that the GPC catchment, pre-GPC status and adult male categories were the reference categories for each independent variable, respectively. Hence the interaction relative rates represent a comparison of non-GPC localities with the GPC catchment area in terms of the change in rates with the opening of the GPC.

The model assumed a Poisson distribution for the number of encounters and an autoregressive (AR1) correlation structure due to the time series nature of the dependent variable. The population for each area, interpolated as described above, was used to define the person-years at risk.

\section{RESULTS}

Relevant results from the GEE are provided in Table 2. The opening of the GPC was associated with a reduction in the quarterly rate of increase in the number of agesex adjusted GP consultations per capita of 1.5 per cent per capita in the GPC catchment, compared to other localities.

These results are also shown in Figure 1 which uses the output of the analysis to calculate the age-sex population size adjusted predicted number of consultations against the quarter for which they apply. The $y$ scale is cardinal but values have been omitted because they are of comparative value only. Lines of best fit have been calculated for each set of data, and the gradients of these lines provided. These have been extrapolated beyond September 1993 for data from the period prior to the opening of the GPC for comparison. The top line represents the western part of Central Sydney Health Area. The opening of the GPC is not associated with significant change here. The middle line represents the rest of the eastern part of Central Sydney Area Health Service. Again, the opening of the GPC is seen to be associated with a non-significant effect. The lowest line represents the GPC catchment area in which the opening of the GPC is seen to have had a significant effect.

\section{DISCUSSION}

The results presented support an association between the opening of the GPC and a reduction in the growth of other GP services provided in the adjacent area. There is no other immediately obvious factor that might explain the differences observed.

The non-significant trend for the existence of the GPC to be associated most strongly with a reduction in growth of demand for primary medical care in its catchment area, less strongly with a reduction in the surrounding eastern part of the Central Sydney Area Health Service, and not at all with the more removed western part of Central Sydney Area Health Service supports the notion of a common link between the two.

In the year from September 1995 to September 1996 there were just under 364,000 encounters billed to Medicare by GPs in the GPC catchment area. According to the analysis there are 1.5 per cent fewer consultations per quarter-that is, 6.0 per cent fewer consultations per annum-in the GPC catchment compared to the other two districts since the GPC opened. If these were due to the GPC then one would expect the GPC to see around six per cent of the encounters seen by GPs in its catchment-that is, 22,000 (95 per cent CI 16,100$26,400)$ encounters per annum. This is the appropriate order of encounters, because the GPC sees approximately 15,000 encounters per annum.

A reason that the number of encounters provided by the GPC is lower than the number suggested by the model is that the GPC provides a 'one stop shop' for patients requiring $\mathrm{X}$-rays. Patients who require $\mathrm{X}$-rays and who see a GP in the community have two encounters with the GP: one to receive an $\mathrm{x}$-ray request and a second to discuss the results and management. Only one visit is required for these purposes for similar patients attending the GPC because the GPC provides on-site radiography services during the day. Patients in the GPC receive an x-ray at 20.9 per cent of encounters. ${ }^{8}$ Were all of these patients to

\section{TABLE 2}

COMPARISONS OF NON-GPC LOCALITIES WITHTHE GPC CATCHMENT AREA-CHANGE OF RATES AFTERTHE OPENING OF THE GPC

\begin{tabular}{|c|c|c|c|}
\hline Comparison & $p$ & Relative Risk & $95 \% \mathrm{Cl}$ \\
\hline $\begin{array}{l}\text { GPC catchment versus the Eastern part of Central Sydney Health Area } \\
\text { GPC catchment versus Western part of Central Sydney Health Area }\end{array}$ & $\begin{array}{l}<0.0005 \\
<0.0005\end{array}$ & $\begin{array}{l}1.015 \\
1.015\end{array}$ & $\begin{array}{l}1.011-1.018 \\
1.011-1.019\end{array}$ \\
\hline
\end{tabular}




\section{FIGURE 1}

NORMALISED USE OF GP SERVICES BY LOCALITY, 1983-1997

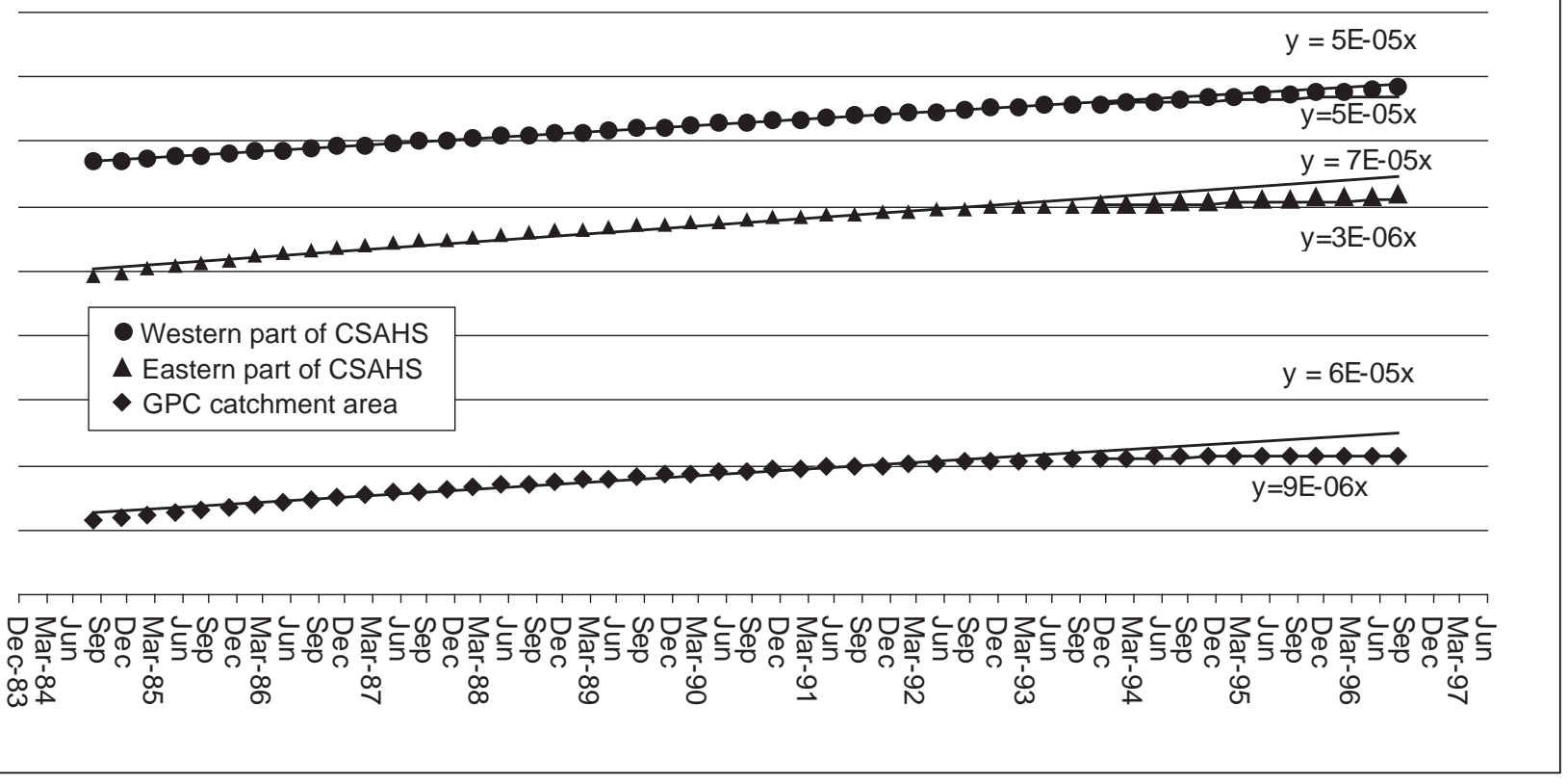

require an additional visit to follow up on their $\mathrm{x}$-rays then the GPC would provide over 18,000 encounters per year.

The analysis and discussion provided suggest that the GPC not only meets patients' needs for primary medical care when their regular GP is not available, but also that it does not duplicate existing services. If it is generalisable then this finding has positive implications for the funding of similar services.

\section{ACKNOWLEDGEMENT}

The assistance of the Commonwealth Department of Health and Family Services in providing data for the analysis is acknowledged.

\section{REFERENCES}

1. Macklin J. A Study of Hospital Outpatient and Emergency Department Services-Background Paper No. 10 (National Health Strategy). Australian Modern Times Pty Ltd, Canberra 1992; 35.

2. Dale J, Dolan B. Cut and Thrust. Health Service Journal 1994; 18 (2): 26-27.

3. Dale J, Dolan B. Do patients use minor injury units appropriately? Journal of Public Health Medicine 1996; 18(2): 152-156.

4. Dale J, Lang H, Roberts JA, Green J, Glucksman E. Cost effectiveness of treating primary care patients in accident and emergency: a comparison between general practitioners, senior house officers, and registrars. BMJ 1996; 312: 1340-1344.

5. Dale J, Green J, Reid F, Glucksman E. Primary care in the accident and emergency department: I. Prospective identification of patients. BMJ 1995; 312: 423-426.

6. Dale J, Green J, Reid F, Glucksman E, Higgs R. Primary care in the accident and emergency department: II. Comparison of general practitioners and hospital doctors. BMJ 1995; 311 : 427-430.

7. Ward P, Huddy J, Hargreaves S, Touquet R, Hurley J, Fothergill J. Primary care in London: an evaluation of general practitioners working in an inner city accident and emergency department. Journal of Accident and Emergency Medicine 1996; 13: 11-15.

8. Bolton P, Mira M, Sullivan M. The Balmain Hospital General Casualty: An alternative model of primary health care provision. Australian Health Review 1997; 20(1): 100-107.

9. Phelps C. Physicians in the marketplace. HarperCollins, New York 1992.

10. Australian Institute of Health and Welfare. Australia's Health 1998-The sixth biennial health report of the Australian Institute of Health and Welfare. Australian Institute of Health and Welfare, Canberra 1998.

11. Commonwealth Department of Health and Family Services. General Practice in Australia-1996. Canberra: Australian Government Publishing Service, 1996.

12. Bridges-Webb C, Britt H, Miles DA, Neary S, Charles J, Traynor V. Morbidity and Treatment in general practice in Australia 1990-1991. Med J Aust 1992; 157: s1-s56. Fit 